\title{
LOS RÍOS PROFUNDOS 60 años después en tres entrevistas
} breves

\section{Juan Valle Quispe*}

elaspirante@gmail.com

Universidad Nacional Federico Villarreal

Resumen: La aparición de Los ríos profundos, en 1958, llevó a José María Arguedas a un puesto imprescindible en la literatura peruana, más aún porque contribuyó a eclosionar, junto con el resto de su obra, un debate en diferentes niveles (con mayor difusión entre los estudios literarios y las ciencias sociales) que perdura hasta nuestros días. Dicho debate también ha servido para conocer el nivel de críticos e intelectuales que aportaron no solo con la comprensión de la novela, sino al desentrañamiento de problemáticas latentes en nuestra sociedad (de esa labor destacan nombres como Tomás Escajadillo, Antonio Cornejo Polar, Mario Vargas Llosa, Carlos García-Bedoya, Gonzalo Portocarrero, Alberto Flores Galindo, William Rowe, Roland Forgues, Ricardo González Vigil, Mauro Mamani, Gonzalo Espino, Dorian Espezúa y muchos más). Afortunadamente, seguimos contando con voces consolidadas en la academia y en la escena literaria peruana que ayudan a enriquecer la lectura de esta novela capital. En esa línea, gracias a Gonzalo Espino Relucé, Nécker Salazar Mejía y Richard Parra, montaremos un breve diálogo con el afán de saber su opinión e indagaciones trascurridas en torno a tan importante novela tras 60 años de haber sido publicada.

Palabras clave: José María Arguedas, crítica literaria peruana, literatura y sociedad peruana, indigenismo.

* Juan Valle Quispe estudió Literatura en la Universidad Nacional Federico Villarreal. Ha sido organizador de diferentes eventos académicos como el Coloquio Anual de Estudiantes de Literatura-UNFV (CAELITUNFV) y participado como ponente en congresos avocados al debate literario. Sus temas de investigación se centran en las propuestas éticas presentes sobre todo en la narrativa contemporánea. Actualmente prepara su tesis de licenciatura. 


\section{GONZALO ESPINO RELUCÉ: "CON LOS RÍOS PROFUNDOS LO QUE CONSIGUE ARGUEDAS ES UNA ESTRATEGIA DE AMPLIACIÓN DE SENTIDOS"}

\section{1. ¿Luego de 60 ańos es posible ver a Arguedas fuera de un proyecto literario que sirva de puente entre el universo andino y un lector ajeno a este, específicamente con la lectura de Los ríos profundos?}

Sí es posible. Vea, el problema con la obra de algunos autores peruanos es que cuando se convierten en clásicos se vuelven lecturas abiertas. ¿Esto qué quiere decir? Que cualquiera de nuestros autores permiten que los abordemos desde diferentes ángulos. Piense usted en la lectura de algún migrante europeo que llega a Arguedas o un chicano de Estados Unidos que lee una traducción al inglés de Arguedas. Creo que su universalidad abre las posibilidades de un acercamiento a una lectura global. Ahora, con Fredy Roncalla coincidimos en un detalle a propósito de Los ríos profundos. El detalle es que puede ser leído como un poema por la forma como la novela está escrita. El lenguaje es un lenguaje rítmico. Es un lenguaje que progresivamente nos va introduciendo a ese universo que Arguedas quiere narrar, que él nos fabula. Si bien hay un núcleo aparente que es el del internado donde llega el adolescente Ernesto y donde conviven todos los conflictos del espacio de una escuela, a su vez, está rodeada, está cercada por lo que sería la ciudad. Y la ciudad está cercada por lo que sería la aldea andina, y eso la hace particular.

\section{2. ¿Podría hablarnos un poco más sobre esta relación entre el personaje y la sociedad} de la que es testigo?

Claro. Al leer la novela, encuentras que Ernesto, quien tiene catorce años y es un adolescente inquieto como todos los adolescentes, se acerca a las chicherías. Y en las chicherías está el mundo andino en efervescencia. Entonces, la novela tiene esta articulación de un sujeto en tránsito como es Ernesto, pero que, a su vez, está confrontando los problemas que se dan desde el espacio urbano en tanto país. Arguedas no necesita explicitar que es el problema del Perú, porque el problema está ahí inmediatamente, en los alrededores comienza. 
Otro ejemplo es el padre de Ernesto, un abogado errante, no tiene un lugar fijo. Allí ves una conexión de la pequeña aldea con otra que no es posible controlarla como sería la ciudad. O sea, los efectos de la ciudad, o de lo que sería el Estado-Nación, están llegando. El Estado todavía no es visible, lo que Morote llama las "aldeas sumergidas"', que dejan de serlo y empiezan a emerger. Es la conectividad que va a tener todo el país. Hoy en día, la aldea más distante que tengamos siempre va a estar conectada al Estado, porque al Estado le interesa cobrar impuestos, por ejemplo, las multas por no ir a votar, etc. Pero para aquel tiempo no, y eso hace que la intensidad de la novela sea vista desde otro plano, ya no desde el plano narrativo sino de lo que la fábula está diciéndonos: lo otro que aparece como contorno. Ya no es solamente el espacio donde se realiza la novela, sino el otro espacio que está rodeando a la novela. Me parece que lo que consigue Arguedas es una estrategia de ampliación de sentidos. La más notable de esta es, sin duda, la rebelión de las chicheras, el problema básico de la sal. Vemos que se produce la revuelta, se redistribuye la sal, ¿pero quién controla la sal? La controla el representante del Estado. El Estado se hace patente en ese acontecimiento. ¿Y quién más está en el control del poder? No solamente es una fuerza civil sino la Iglesia y ese momento de la novela me parece extraordinario: el que va a apaciguar es el cura, el cura que va a perdonar los pecados, de un pecado que nunca han cometido desde nuestra perspectiva. Pero es también el cura que nunca va, que no está en la comunidad, porque es el cura que va a llegar solo en cada fiesta, cada temporada, pero nunca está presente. Entonces, es una santificación. Además, las palabras del cura, quien habla en quechua. Habla desde la perspectiva del viejo extirpador de idolatrías y lo vuelve contemporáneo, lo vuelve actual. Aunque ya no es el discurso solamente eclesiástico sino un discurso que va paralelo al del Estado.

3. ¿Cree que el proyecto con el lenguaje en la novela, aquella "andinización del castellano" (Relucé, 2007, párr. 8) ${ }^{2}$ que usted ha llegado a mencionar en su producción escrita, tiene su punto más álgido en esta novela a diferencia del resto de la producción de su autor? ¿̨odría explicarnos un poco más acerca de este término?

1 Morote Best, E. (1988). Aldeas sumergidas: cultura popular y sociedad en los Andes. Lima, Perú: Centro Bartolomé de las Casas.

2 Espino Relucé, G. (2007). José María Arguedas, metáforas de la escritura. La alforja de Chuque. Recuperado de https://gonzaloespino.blogspot.com/2007/05/jos-mara-arguedas.html 
Para empezar, todos nuestros escritores han tenido un problema, el problema de cómo escribir desde una lengua que permita dialogar con el peruano común. Porque una lengua culta como teóricamente se enseña en la academia, no es suficiente para expresar la sensibilidad de una población. Entonces, Arguedas, y Vallejo en particular, son dos de nuestros narradores y poetas que se empeñan en eso. En el caso de César Vallejo uno podría aludir a lo que dice Enrique Foffani, un académico argentino de la UBA, cuando señala que Vallejo es un escritor arcaico porque el castellano que va a usar, la lengua que va a usar, tiene muchos arcaísmos. Es un lenguaje del pasado que no es legible para la ciudad. Pero es el castellano que se utiliza en el norte del Perú. Entonces, aparece como un castellano que no es domesticado, es como un quiebre con el castellano standard que se está usando. Eso hace su escritura barroca, según Foffani.

Pero eso no es todo, porque al ser un castellano con esta marca de localismos y arcaísmos hace que explote en términos de sentidos. Con ese castellano, Vallejo tiene que construir su dicción poética en Los heraldos negros o Trilce. Ese castellano se convierte en una dinamita, explota con sentidos nuevos. El lector de la ciudad se siente extrañado, un lector local no. Al lector local le suena bien y no ve la parte más interesante de la poesía universal de César Vallejo, la capacidad de dinamizar el lenguaje, de renovarlo. De ese modo, Arguedas por el año 39 escribe su famoso ensayo sobre el tema de la lengua ${ }^{3}$ ¿ Y a quién toma como referente? A Vallejo. Encuentra que es el primero que ha asumido el reto del lenguaje y sería la primera manifestación de la lengua andina en la época. ¿Por qué? Porque en ese momento estamos asistiendo a la transformación de esta lengua castellana con características aristocráticas, muy de ciudad, muy de la pequeña aldea de ciudad (Lima, Trujillo, Arequipa, Cusco, Huamanga, para citar algunos núcleos donde se desarrollan con bastante afluencia la cultura).

Este castellano es el que va a ser resquebrajado. Ese mismo castellano es el que Arguedas está tratando desde Agua. Debido a lo que considera fracasos en ese libro, comienza a reescribir. Ves que hay muchas aclaraciones desde su primer libro, muchos reenvíos aclarativos para explicar lo que quiere decir. Este proceso lo vas a encontrar también en Canto quechua. En este libro sabe que lo hay que poner en cuestión es el problema del indio. ¿Cuál es el problema del indio? El problema de la tierra, pero también lo que se ha construido como imaginario: el indio es triste. Y Arguedas insiste en que no lo es. Al añadir

3 Arguedas, J. M. (1939). Entre el kechwa y el castellano: la angustia del mestizo. La Prensa. Buenos Aires. 
los cantos, su objetivo es trascribir, no traduce necesariamente. Está recreando la poética, lo cual es trascribir, tras-crear. Trascribe el quechua y tras-crea al pasarlo al castellano. Después lo vemos con Yawar Fiesta, donde también hay un discurso en el que no tiene esa vivacidad, pero acierta en los sentidos de la construcción de los ejes narrativos que debe tener una novela. Y cuando llegamos a Los ríos profundos estamos ante otra manera de construirlo. Y de esa misma manera se vuelve hipervanguardista cuando leemos El zorro de arriba y el zorro de abajo, que es un libro en el que el sujeto desborda, donde la escritura ha llegado a ocupar el espacio de lo que puede decirse en la palabra. La palabra se vuelve una actualización de lo que se está viviendo en ese momento.

\section{En su opinión, ¿qué tanto valor se ha dado a la fuente testimonial (cartas, diarios, entrevistas, conferencias $)^{4}$ respecto al análisis de los elementos poéticos en Los ríos profundos?}

Creo que en algunos casos se ha exagerado como lo que ocurrió en el Instituto de Estudios Peruanos. Me parece que es exagerado. Creo que una lectura como la que hace Dorian Espezúa es importante porque comenta puntos que no han sido dichos. Sin embargo, lo testimonial no siempre te dice lo que quisieras encontrar en un texto. Lo que nosotros, en todo caso, debiéramos tener en cuenta es que los paratextos siempre son pretextos. El testimonio puede tener distintas orientaciones. Un escritor crea su perfil. Puede crear el perfil del que está siempre dolido, que está agobiado, que tiene problemas como era Arguedas mismo, con crisis permanentes. Pero tú lees sus textos y son otra cosa. Hay que evitar confundir la vida con el texto, la vida es un pretexto, pero no es el texto. Son dos relaciones diferentes. El tema es la exageración. Por ejemplo, creer que el suicidio de Arguedas explica El zorro de arriba y el zorro de abajo. La característica de los zorros es su vanguardismo. Encuentras que no hay fronteras. Tú indagas en los diarios y cartas y las puedes encontrar en la vida real, pero el estatuto ya cambió. El estatuto es el estatuto de una ficción, porque ya no pertenece a este periodo que pertenece a la época que Arguedas vivió. ¿Acaso esta nueva generación de lectores lo va a leer como eso? Su clave de lectura no va a ser esa sino

4 Sobre este último elemento del paréntesis, puede verse Espezúa Salmón, D. (2008). Contra la textolatría. Las motivaciones creativas en los testimonios de Arguedas, Alegría, Churata e Izquierdo Ríos. Letras, 79(114), 81-106. Recuperado de http://revista.letras.unmsm.edu.pe/index.php/le/article/view/141/140 
la de un sujeto humano, sensible, capaz de percibir las atrocidades del capitalismo, de las desigualdades.

\section{Quizá una de las categorías más difundidas en torno al estudio del personaje de Ernesto es la del Wakcha. A la luz también de los pasajes líricos de la novela, ¿cómo ve el estado actual que la academia le da a esta categoría?}

Con Fredy Roncalla nos hemos propuesto volver a revisar esta categoría. Sin embargo, lo que te puedo decir es que la potencialidad de esta categoría tiene que ver con la condición humana. Un hombre andino que no tiene un referente, que no tiene un apellido, un andino que no tiene lo necesario para vivir es literalmente alguien que no se ha desarrollado como humano. Imagínate una persona del ande que no tiene un ayllu (una familia), ¿quién lo protege? Que no tenga un apellido, en tiempos contemporáneos la ONPE lo estaría persiguiendo. A alguien que no tiene nada, la SUNAT estaría preocupada porque no tendría a quién cobrar. Tiene que ver con elementos de la constitución del ser humano en tiempos contemporáneos. Lo que quiero decir es que esta categoría aún tiene potencialidad porque en toda la producción narrativa de Arguedas hay situaciones que se vinculan a la categoría del Wakcha.

Lo que en líneas generales sí podemos afirmar es que la narrativa de Arguedas siempre se centra sobre un elemento específico, pero si posicionas tu lectura desde el propio texto. Hay un elemento que siempre está presente, pero la concepción del sentido de esta narrativa no se produce solamente en el relato, se produce en diálogo con lo que está ocurriendo. Es lo que te decía hace poco con la revuelta de las chicheras. Nos advierte de eso, la condición del poder del Estado y su triada: el juez, el cura y el gobernador. Es una fuerza que no está sola. Arguedas no necesita decírtelo, lo puedes leer. Aquello que es una aldea cerrada y lo que está ocurriendo ahí. 


\section{NÉCIKE SALAZAR MEJÍA “LOS RÍOS PROFUNDOS AFIRIMA NUESTRO LEGADO ANDINO Y LO QUE SOMOS COMO NACIÓN"}

\section{1. ¿En qué medida puede modular la identidad de un peruano la lectura de Los ríos profundos, 60 años después de haber sido publicada?}

La obra de Arguedas es una indagación y búsqueda de lo que es y significa el Perú. Nuestro país es un país diverso y pluricultural; la obra de Arguedas demuestra que, en esa complejidad, tiene un lugar importante la cultura andina, pues el Perú es un país de marcada raíz andina, lo que no está en contradicción con la pervivencia y manifestación de las otras herencias culturales que existen dentro de él. El legado de la cultura andina se puede observar en la vigencia de sus tradiciones, la vitalidad de sus expresiones artísticas y musicales, la afirmación de sus valores, etc.

Considero que la lectura de Los ríos profundos puede contribuir a afirmar nuestra identidad y a entender la gran vitalidad de la cultura andina, tal como se expresa en las otras obras de Arguedas. Es una novela que muestra la riqueza de la cultura andina, la relación vital entre el hombre y la naturaleza, la fuerza expresiva de la música, las creencias del universo andino, la gran complejidad y riqueza que caracteriza al mundo andino. En tal sentido, la novela de Arguedas afirma el legado andino como parte esencial de nuestra identidad y de lo que somos como nación.

\section{Después de todos estos años, ¿qué representaciones y manejos del poder visibilizados} por Arguedas en Los ríos profundos cree que persisten en la realidad andina?, ¿̨han cambiado para bien o se han mantenido bajo otras formas?

Es interesante observar que en el mundo representado por Arguedas existe una jerarquización que se aprecia en las relaciones que establecen los alumnos y en la manera como se ejerce la autoridad por parte del P. Linares. Desde esa perspectiva, efectivamente, podemos apreciar en la novela una diversidad de relaciones que tienen un carácter contradictorio. En ese sentido, hay una imagen autoritaria, por ejemplo, del estamento religioso que está en contradicción con los valores de reciprocidad que comparten, por su parte, los estudiantes. 
El P. Linares, en gran medida, favorece una educación que se vincula con los hacendados y, por ello, ejerce un cierto sesgo entre los alumnos del colegio.

Por otro lado, la novela ofrece una serie de representaciones sobre cómo se maneja el poder, por ejemplo, en el caso de la rebelión de las chicheras, así como otras situaciones en las cuales se busca favorecer la imagen del poder que tienen los hacendados. De tal manera que, en gran medida, ese universo de relaciones de jerarquización y diferenciación que se perciben en el mundo representado se corresponde con formas de dominación que se reactualizan en el tiempo presente en la realidad andina.

3. En sus tesis de doctorado afirmó que tanto Arguedas como Ciro Alegría comparten tres niveles, propuestos por Cornejo Polar, desarrollados en el indigenismo: "el modo de composición”, “el componente lírico” y "los componentes míticos” (Salazar Mejía, 2015, p. 54) ${ }^{5}$. En el caso de Los ríos profundos, ¿̨ree que todos estos componentes se dan en un mismo rango o se podría decir que hay niveles mucho más expuestos que otros?

Entre los elementos que Cornejo Polar establece para definir la narrativa indigenista, menciona estos tres niveles. Con algunos matices, se puede observar esta caracterización en las novelas de la literatura indigenista, como las obras de Alegría y Arguedas. En el caso específico de Los ríos profundos, existe una secuencia aditiva como estructura compositiva, ya que se observa una cierta tendencia a la autonomía de los capítulos, que se debe a la influencia del cuento; al respecto, recordemos que Arguedas publicó un capítulo de manera independiente. Sobre los elementos líricos, la novela nos da a conocer una importante selección de canciones quechuas, así como de los géneros musicales propios del mundo andino. Lo mítico está presente en varios episodios de la novela, por ejemplo, cuando se invoca a los apus tutelares, en la articulación mágica entre el mundo, el hombre y la naturaleza, en la cosmovisión andina, etc.

Salazar Mejía, N. (2015). Tradición oral y memoria colectiva en la novelística de Ciro Alegría (Tesis doctoral, Universidad Nacional Mayor de San Marcos, Lima, Perú). Recuperada de http://cybertesis.unmsm.edu.pe/ bitstream/handle/cybertesis/4588/Salazar_mn.pdf?sequence $=1$ \&isAllowed=y 
4. Usted ha llegado a escribir sobre la propuesta que Arguedas tuvo como docente en el Colegio Mateo Pumaccahua en Sicuani, etapa anterior a la aparición de esta novela $^{6}$. En su faceta como escritor, además de varios de sus cuentos, en ningún otro texto Arguedas da una atención tan grande al ámbito escolar. Sobre ello hay una dicotomía en la novela de la que quisiéramos que nos comente: aquella de la realidad de la propuesta docente, a través de los hermanos profesores, contrastada con la realidad de los compañeros con los que convive Ernesto.

El ámbito escolar es clave en Los ríos profundos, ya que es una novela que narra la historia de un grupo de escolares en un colegio religioso de Abancay. Se puede observar una diferencia entre la orientación de la educación que impulsan los hermanos religiosos que están a cargo del colegio y los valores que están asociados con los estudiantes. El P. Linares promueve una educación en la cual él ejerce la autoridad y favorece las diferencias sociales; además, tiene un control sobre los indios mediante la palabra, la oratoria y el empleo persuasivo de los conceptos y pensamientos indígenas. Ernesto tiene, por el contrario, una actitud opuesta hacia el P. Linares, ya que simpatiza con el reclamo de las chicheras, siente preocupación por la Opa Marcelina, su pensamiento posee un sentido más humano y cree en la justicia y equidad entre los hombres.

5. En la misma ponencia, usted afirmó que Arguedas apostaba por una educación que estuviera acorde con las raíces culturales de los niños indios, que diera lugar al pensamiento crítico y el debate. Esta propuesta que también sirve para criticar los modelos educativos que veía en esos años, se refleja no solo en la actuación de los frailes maestros de Los ríos profundos. El caso del personaje Valle, aunque breve, es bastante preciso, ya que es un alumno que antagoniza el modelo educativo de Arguedas al ser un muchacho alienado, adepto a los poetas modernistas, a la filosofía de Schopenhauer, pero sobre todo por desdeñar el quechua y aspirar una vida fuera de la realidad andina.

6 Se trata de la ponencia "La escuela como espacio de creación en el pensamiento de Arguedas". Este texto fue leído en el Congreso Internacional "Los universos literarios de José María Arguedas". El evento fue organizado por la Escuela y el Departamento Académico Profesional de Literatura de la Universidad Nacional Mayor de San Marcos en el 2011. Lamentablemente aún no se han publicado las actas. 
Es interesante la labor de Arguedas como docente e investigador de las tradiciones culturales del mundo andino, lo que se expresa en sus ideas sobre la educación y en sus trabajos de recopilación y de rescate de la literatura oral. Para Arguedas, es importante fomentar una educación centrada en la cultura y los valores andinos, lo que lleva a cabo en su experiencia pedagógica en el Colegio Mateo Pumaccahua. Desde esta perspectiva, planteaba una alternativa distinta, y en gran medida, se adelantaba a los tiempos actuales. El caso del alumno Valle es un caso singular, ya que, efectivamente, su interés está más abocado a la lectura y al gusto por la literatura y el pensamiento occidental, además de que era un alumno que no hablaba la lengua quechua. Si bien el conocimiento de la tradición occidental es importante, en la ficción en cierta forma se contradice el tipo de estudiante que Arguedas había impulsado en su trabajo docente, más identificado con el entorno local y la cultura andina, sus fiestas y tradiciones.

\section{Como investigador de la literatura indigenista, ¿podría hacer un balance de qué tan activa es la recepción de esta novela en las aulas de estudios de posgrado?}

En los estudios de posgrado, Arguedas es un autor que siempre genera interés y nuevas indagaciones. Tanto investigadores como maestristas o doctorandos han realizado importantes trabajos sobre la obra arguediana. Arguedas es un escritor que siempre ha motivado grandes debates en los estudios de posgrado. Sobre la obra arguediana, se pueden citar las tesis de Voces y discursos en el Zorro de Arriba y el zorro de abajo, el largo camino hacia el diálogo de Jéssica Rodríguez y Mito y modernidad en "El zorro de arriba y el zorro de abajo" de José María Arguedas de Henry Riva; entre las tesis centradas en Los ríos profundos, se puede mencionar la tesis de Moisés Córdova, El universo mágico en Los ríos profundos de José María Arguedas, que luego se publicó bajo la forma de libro; después tenemos la tesis La antitesis del mundo civilizado en Los Ríos Profundos de José María Arguedas y el Gran Sertón Veredas de Guimaráes Rosa de Raisa Zirena; todas ellas se han sustentado en los últimos años.

7. En su rol como catedrático de dos de las cuatro universidades en el Perú donde se ofrece la carrera de Literatura (UNMSM y UNFV), ¿̨ómo ve la atención que las jóvenes promociones tienen hacia Arguedas?, ¿es solo visto como un autor de rigor o hay una atención más allá de las horas de clase? 
En general, el interés por la vida y la obra de Arguedas se ha mantenido constante en el medio académico, más entre los estudiosos y los críticos arguedianos. Considero que sigue siendo un escritor fundamental en la literatura peruana y, por ello, su lectura es de rigor. Sin embargo, tengo la impresión de que las promociones jóvenes, si bien estudian y quieren conocer la obra arguediana, se inclinan más por escritores contemporáneos, se centran en el estudio de otras tradiciones, no propiamente en la narrativa indigenista, y están más influidos por las nuevas direcciones que surgen en la literatura. Pese a ello, creo que siempre existe un interés por el estudio de las obras de Arguedas. 
JUAN VALLE QUISPE

\section{RICHARD PARRA: "SE LEYÓ Y SE LEE LOS RÍOS PROFUNDOS DESDE UN IRRESPONSABLE CONSENSO"}

\section{1. ¿Después de $\mathbf{6 0}$ años, cuál que cree que ha sido el aporte teórico más importante que ha traído la reflexión sobre Los ríos profundos?}

Creo que en cierto momento la reflexión sobre esta novela estuvo estancada. Cuando preparaba mi tesis de licenciatura sobre Arguedas, hace una década, un reputado profesor posmoderno de la PUCP me preguntó por qué volvía a esta novela, dando a entender que su discusión estaba hasta cierto punto cerrada. Los cien años de Arguedas fueron motivo de celebración, pero no de una relectura rigurosa actual. Los 50 años de la publicación de Todas las sangres pasaron totalmente desapercibidos, en parte porque es una novela ninguneada $\mathrm{y}$, por qué no decirlo, odiada.

Después del agresivo panfleto de Vargas Llosa, La utopía arcaica (publicado en pleno auge del neoliberalismo), la obra de Arguedas en su conjunto fue vista bajo ojos individualistas, presuntamente morales. Se la sometió a un proceso, en el sentido kafkiano del término, ideológico retroactivo. No sorprende por ello que se lea a Arguedas desde el puritanismo posmoderno, desde las políticas de la identidad liberales, desde categorías enclenques como "autoficción", y desde el multiculturalismo norteamericano.

Se la redujo, por ejemplo, a novela paisajista; a expresión nostálgica de una "utopía arcaica"; a obra de arte "indigenista"; a intertexto antropológico; a expresión de una literatura local, peruanista; a paradigma de una idea ingenua — sin antagonismos de clase ni culturales ni políticos — de mestizaje; se la encorsetó bajo el falsificado y mercantil eslogan de un "Perú de todas las sangres", muletilla invocada cada cuanto por políticos nefastos y comisarios de la cultura.

O, peor aún, se la catalogó con las categorías comerciales y vacías de "realismo mágico" o "realismo maravilloso" y hasta de "literatura fantástica", llegando comparar el Zumbayllu con una suerte de Aleph folklórico, o describirlo como un collage surrealista. Se leyó y se lee Los ríos profundos desde un irresponsable consenso, desde una delirante armonía que cada día la realidad niega. 
En tal sentido, nociones como las de "armonía imposible" planteada por Cornejo Polar, o la de "yawar mayu" (propuesta por el propio Arguedas) y desarrollada por Carlos Huamán $(\text { Pachachaka })^{7}$, y hasta cierto punto por Eduardo Subirats (Mito y literatura) ${ }^{8}$ son lecturas estimulantes de Los ríos profundos.

Desde la narrativa, la poética de Miguel Gutiérrez, en textos como La violencia del tiempo o Celebración de la novela, rescata una concepción panteísta, holística, spinoziana de la novela contemporánea, que, en opinión de Gutiérrez, también tiene como fuente generatriz a Arguedas.

Desde el arte, por ejemplo, el muralismo de Josué Sánchez relee la mitología popular cimentada en las novelas de Arguedas, sobre todo la noción sagrada de la Naturaleza y los mitos creadores. Lo que quiero subrayar brevemente es que una lectura contemporánea de Arguedas debe ser multidisciplinaria, alejarse del formalismo escritural autotélico.

\section{2. ¿Podría hablarnos de la principal dificultad que encontró al leer por primera vez la novela?}

¿Una seria dificultad? Ninguna. Es una novela clara, esclarecedora, con una compleja estructura, que al mismo tiempo superpone la narración mítica e histórica, pero también es un relato clásico, con un héroe, un antagonismo social, cultural, político y un desenlace abierto que sitúa al protagonista Ernesto en una nueva situación tensa, un final que privilegia desencuentros, paradojas y conflictos antes que edificantes utopías.

El drama de Los rios profundos, sus aspectos culturales, su lenguaje, su música, la plasticidad de sus materiales, la vitalidad de la Naturaleza son transparentes. Niegan la cultura cristiana colonial barroca, el escolasticismo letrado de la literatura virreinal. Sin embargo, no por ello debe descontextualizarse la novela, desligarla de las luchas de clases en los Andes de los inicios del siglo XX, de las dictaduras de Leguía a Odría, de la crítica de la república aristocrática y del antifascismo de Arguedas por el que estuvo preso. Mucho

7 Huamán, C. (2004). Pachachaka. Puente sobre el mundo. Narrativa, memoria y símbolo en la obra de José María Arguedas. Ciudad de México, México: El Colegio de México, Centro de Estudios Lingüísticos y Literarios.

8 Subirats, E. (2014). Mito y literatura. Ciudad de México, México: Siglo XXI Editores. 
menos del pensamiento mítico andino, del carácter colectivista de la visión poética, musical y social de Ernesto, del pensamiento crítico de Mariátegui — que circunscribe la política arguediana-, o del humanismo anticolonial del Inca Garcilaso.

La lectura de una novela como Los ríos profundos desmantela la (tristemente dominante) noción oportunista del "simple lector", una matriz de opinión demagógica impulsada por la pseudocrítica periodística. La lectura de Los ríos profundos, como su estructura poética, es la de un viaje iniciático, una experiencia que exige una recepción activa, creadora, una intervención en la obra.

\section{En debates o discusiones en su estancia en USA, ¿encontró alguna lectura de un escritor extranjero que leyó Los ríos profundos la cual le haya impactado hasta ahora?, ¿fueron todas positivas?, ¿encontró un consenso o posición general?}

El posmodernismo y el formalismo actual (ya en decadencia por fin) dejó de lado toda una tradición literaria fuera de debate. Por ejemplo, Arguedas, Guimarães Rosa (un arguediano) y el Inca Garcilaso. Si se leía Arguedas, era para revisar un pasado que supuestamente se estaba superando, para deconstruirlo con un manual de teoría literaria traducida, no para desde sus más radicales materiales transformar el presente literario y cultural. Ejemplos de las más ramplonas lecturas del Arguedas de Los ríos profundos son aquellas que presentan a su autor como un "romántico" o como "un autor de culto" o que intentan "cuestionarlo" a través del arte pop de Andy Warhol.

La lectura más canónica en Estados Unidos puede ser la de Ángel Rama. Me refiero a la noción de "Transculturación", tomada a su vez del intelectual cubano Fernando Ortiz, es decir una lectura antropológica, pero domesticada a los intereses reaccionarios post-ideológicos de la máquina académica estadounidense. Este sería el caso de Mary Pratt (NYU) y su libro Imperial Eyes, donde desarrolla conceptos como "zonas de contacto", tomado a su vez de Rolena Adorno (Universidad de Yale) y su noción liberal protestante de "individuo con sus propios intereses" y "negociación”; criterios ambos que Adorno empleó para leer a Guaman Poma, minimizando la tan importante noción de reciprocidad y sujeto colectivo presente en sus novelas y cuentos.

Es decir, se leía a Arguedas desde categorías externas al contexto cultural de donde emergió: en mi concepto no se puede leer la subjetividad de Ernesto en Los ríos profundos 
con ojos cartesianos o concibiéndolo como un "homo economicus". Por eso creo que a Arguedas ya se lo asumía como monumento cultural estático, no como materia animada, ni como la misteriosa música que es. Arguedas era y es, lamentablemente, objeto de prueba de improvisadas categorías críticas, no generador de horizontes de lectura, pensamiento crítico, formas literarias y civilización.

En NYU tuve la oportunidad de escuchar las clases de Eduardo Subirats, quien, desde la teoría crítica, y desde una perspectiva mítica, interdisciplinaria e historicista, ha escrito uno de los ensayos más estimulantes sobre Los ríos profundos de los últimos años, incluido en su notable libro Mito y literatura. También tuve la oportunidad de conocer a la novelista Diamela Eltit, quien no solo nunca dejó de expresar su admiración por Arguedas, sino que estimulaba que se lo leyera desde la realidad cultural y política presente.

\section{4. ¿Ha deslindado o pronunciado en contra de alguna lectura o lecturas venidas de la academia sobre Los ríos profundos?}

En principio, con la que propuse en mi tesis de licenciatura de la PUCP. El mayor error de ese trabajo en su últímo capítulo fue hacer lo que ahora tanto rechazo: transplanté subalternamente, como es la práctica común en los departamentos academicos de "estudios culturales", conceptos prestados de la academia global: la noción de soberanía, poder y estado de excepción del foucaultianismo de Agamben para leer el complejo final de Los ríos profundos: ¿el resultado?, la neocolonización de la novela, su uso ancilar, la degradación de Ernesto a un sujeto cartesiano, agente de un individualismo burgués liberal, incapaz de integrarse al colectivo si no a través de inoperantes directrices: populismo, poscolonialidad y multiculturalismo.

Recientemente he criticado la lectura de Juan Carlos Ubilluz de Agua. Un inteligente close-reading que, sin embargo, se somete a la hegemonía académica de Lacan y sus glosadores. Uno de los resultados, sintomáticamente, es paralelo al que Vargas Llosa desde el neoliberalismo concluyó en La utopía arcaica: vincular el Yawar Mayu, el Pachacuti, los movimientos de resistencia y revolucionarios contenidos en los relatos de Arguedas, nada menos que con el mesianismo totalitario de Sendero Luminoso, a su esquizofrénica lucha de clases estalinista, cuestión que Arguedas criticó duramente en El Sexto. 


\section{A nivel de técnica, ¿cuál cree que ha sido el aspecto menos valorado o desapercibido por la academia en torno a Los ríos profundos?}

El deslinde entre la forma y la materia narrativa es una gastada y exagerada herencia de la estilística, escuela crítica literaria dominante en la España franquista. El posmodernismo gramatológico francés también es una escuela formalista que además de deshistorizar, reduce la mitología y las culturas populares históricas contenidas en una novela como Los rios profundos a "ficción", "intertexto", o "simulacro lingüístico".

Ya un autor tan notable como Julio Ramón Ribeyro, a pesar de cierto burocratismo criollo que su imaginación literaria a veces destila, criticó por ejemplo la "falta de unidad" de Los ríos profundos. Es decir, Ribeyro le reclamaba a Arguedas una novela con una forma administrada, un plot aristotélico, un libro que no perturbe formas y protocolos escriturales, o sea, una literatura concebida con criterios industriales, aquella escritura de decálogo. Esa calificación de Arguedas como escritor primitivo, premoderno la comparte el Vargas Llosa neoliberal. En los sesenta y setenta, Vargas Llosa destacó como un atento lector de Arguedas, todo eso acabó con su pasó al thatcherismo.

En Los rios profundos, Arguedas produce un arte que combina la tradición oral histórica, el realismo crítico, la música, la poesía. Es un libro de viajes, una memoria personal de la tiranía colonial, un coro polifónico de voces antagónicas, pero no es un libro de tesis, como El tungsteno, ni un riguroso pasatiempo formal letrado como El hablador.

Como en sus demás novelas, en Los ríos profundos se percibe no una forma preestablecida, sino una lucha por ella. Arguedas no asume una literatura tecnocrática, aquella que parte de gadgets diegéticos, de plantillas narratológicas, aquella narrativa fordiana del procedimiento que tanto pregonan Aira y Bellatin. Los materiales narrativos de Arguedas, sus relatos míticos y su perspectiva literaria, musical, están en constante conflicto. Hay brechas entre ellas y es allí donde su energía literaria no se agota, donde los lectores del presente pueden redescubrirlo.

Yo leo Los rios profundos dialécticamente, y su descenlace naturalmente no es una forma legible, un libro escolástico, basado en dogmas y repeticiones. Esta lucha por la forma literaria se intensifica en Todas las sangres y llega a un catártico radicalismo en El zorro de arriba y el zorro de abajo. 
6. ¿Cómo imagina al Arguedas lector que escribe esta novela? En su correspondencia (Portugal, 2007, p. 212) ${ }^{9}$, afirma haber leído, entre otros, a Steinbeck, Dos Pasos, Faulkner (González Vigil, en el estudio que le dedica para la edición de Cátedra a esta novela, menciona varios puntos que la relacionan con Las palmeras salvajes de Faulkner) ${ }^{10}$. ¿Qué relaciones rastrea entre estos o tal vez otros escritores al leer la novela?

La reducción del escritor al lector es una tarea que han venido haciendo autores como Piglia y Sarlo, por ejemplo, en su empeño por digerir y controlar filológicamente la prosa borgiana, de desligar a Borges de sus condiciones históricas, económicas y de clase. Es un proyecto teorizado por Derrida en De la gramatología, libro donde plantea la tesis de que la oralidad ya es una forma escritura, a la cual por supuesto se accede por medio de "la lectura". Arguedas está lejos de esta escolástica. Él mismo dice que aprendió relatos, adivinanzas y canciones quechuas en la cocina de su casa rodeado de indias. Pero leyendo Los ríos profundos uno identifica fuentes de diversos tipos no solo "literarias": libros de viajes, reportes antropológicos, bitácoras naturalistas, catecismos misioneros, crónicas coloniales. La novela muestra, asimismo, un conocimiento sociológico profundo de la realidad colonial andina, del siniestro gamonalismo, de sus aparatos materiales e ideológicos de poder, de las formas políticas andinas, de las luchas internas entre los sectores oprimidos, así como del repertorio musical peruano. Su desmantelamiento de esa institución bárbara y criminal que era la hacienda andina solo tiene comparación con la crítica del sistema carcelario de Foucault, o con la crítica de las plantaciones de esclavos propuesta por Gilberto Freyre en Casa-Grande e Senzala. Como toda novela moderna, Los ríos profundos se alimenta de una constelación de materiales, no solo de "ficción".

Como poeta y novelista, su manejo del español, de su lengua literaria híbrida entre quechua y español, y de las formas literarias clásicas es evidente. Pero hay un elemento que distingue a Arguedas: su lengua se desafía a sí misma, por eso entre novela y novela hay fuertes variaciones estructurales y poéticas. La de Arguedas es una palabra que trabaja en sus márgenes y límites.

9 Portugal, J. A. (2007). Las novelas de José María Arguedas. Una incursión en lo inarticulado. Lima, Perú: Fondo Editorial de la Pontificia Universidad Católica del Perú.

10 Arguedas, J. M. (2006). Los ríos profundos (Ed. González Vigil, R.). Madrid, España: Cátedra. 
En Los ríos profundos, Arguedas se muestra como un atento lector del Inca Garcilaso sobre todo, pero también de Guaman Poma, de Cervantes, de Guimarães Rosa, de Rulfo, de Vallejo. Yo encuentro también ecos de Proust, de Hugo, de Dostovieski, del muralismo social de inicios de siglo.

Ahora bien, me llama la atención que se quiera forzar a un vínculo con literatura norteamericana de inicios del siglo XX como garantía de modernidad estética de Arguedas. En principio, más allá de la indiscutible calidad literaria de esos escritores estadounidenses globales que menciona (todos ellos hombres blancos, cabe apuntar), tanto Arguedas, como Borges, Rulfo, Rivera, Churata, Baldwin, Roth, Lispector, Toni Morrison, Donoso o Eltit, o cualquier escritor no subalterno, exige leersele desde su contexto cultural, desde su especificidad histórica, no solo desde supuestas redes cosmopolitas, a veces tan o más ficcionales que las obras de arte que supuestamente las materializan. Harta, da risa y empobrece escuchar cosas como el Knausgård de Miraflores, o el Carver de Pando, o el Bolaño del bar Queirolo.

Volviendo a la pregunta, pues claro que encuentro relaciones entre Los ríos profundos y el mundo devastado y sin esperanzas descrito en Grapes of Wrath, o con la estructura mítica ligada al sagrado río de Wild Palms, o con la dura crítica social de ese primer Dos Passos en Manhattan Transfer, pero estos también son intereses que surgen en situaciones de postguerra y postcrisis. Arguedas no solo vivió la degradante realidad andina del gamonalismo, el asfixiante subdesarrollo colonial del Perú, su dependencia imperial de USA, sino también estuvo preso bajo la dictadura filofascista de Benavides. Republicano declarado en el contexto de la Guerra civil española, y socialista hasta su trágico suicidio, perteneció a una generación que, con aciertos y tropiezos, modernizó y superó por fin el carácter satelital de la narrativa peruana. 